\title{
Isolation And Identification Of Microorganisms Involved In The Spoilage Of Soymilk
}

\author{
Mbajiuka Chinedu Stanley ${ }^{1}$,Obeagu Emmanuel Ifeanyi ${ }^{2}$, Ifediora A.C ${ }^{1}$ and \\ Ugwu Getrude Uzoma ${ }^{3}$ \\ 1.Department of Microbiology,Michael Okpara University of Agriculture,Umudike,Abia State,Nigeria. \\ 2.Diagnostic Laboratory Unit,University Health Services Department, ,Michael Okpara University of \\ Agriculture,Umudike, Abia State, Nigeria. \\ 3. School of Nursing Science, ESUT Teaching Hospital Parklane Enugu, Nigeria.
}

\begin{abstract}
Locally produced soymilk was subjected to microbiological analysis(under two storage conditionsambient and refrigeration) to ascertain their hygienic standard of production and the and the shelf life.Standard microbiological techniques,pour plate method were used in the enumeration of potential spoilage organism in soymilk sample.Result of microbial analysis showed that activities of microorganism were more pronounced in the sample kept at ambient temperature $\left(27^{0} \mathrm{C}\right)$ with bacterial count of $2 \times 10^{3}$ on the first day after production but later increased to $2.9 \times 10^{4}$ after six days of storage. There was outstanding difference in the bacterial count of the refrigerated sample as none was observed in the first day after production but later increased to $1.5 \times 10^{4}$ after the sixth day.Result obtained showed that soymilk can be kept for up to three(3) days at refrigeration temperature $\left(4^{0} C\right)$.Seven bacterial isolates,Bacillus spp,Enterobacter spp and Escheria coli and three fungal isolates.Aspergillus spp,Rhizopus spp, and Penicillum spp were detected in the soymilk stored at both ambient and refrigeration conditions. The microbial population detected in terms of number and types of microorganism reflected poor hygienic standard of production,constituting a public health hazard among the consumers. The result of statistical analysis carried out revealed that there was significant treatment effect on the growth of microorganism. The implication of this study is that the quality of locally produced soymilk needs to be critically monitored to avoid transmission of infection to consumers.It is also very necessary that local producers should be enlightened about good manufacturing practices and the effect of proper storage as this will ensure products free of pathogenic microorganisms.
\end{abstract}

Keywords: Soymilk, microbiological spoilage, storage conditions and Pathogens.

\section{Introduction}

The diets of people in many developing countries comprise mainly starchy roots, cereals, and few legumes. Unfortunately, animal sources of protein, which are used to complement the starchy diets, are expensive and times, out of reach for low income families (Kolapo and Oladimeji, 2008). In recent years, different edible varieties of legumes have been identified to have high plant protein, and therefore could help to address a number of diet related problems globally. Grain legumes serve as a cheap source of proteins to a large proportion of the population in poor countries of the tropics. Several legume based milk and milk products have been developed in attempts to extend the supply of milk-like products especially in areas where milk is in short supply. Since legumes are important sources of relatively inexpensive protein, introduction of imitation milk products from legumes will contribute to the alleviation of protein malnutrition (Gesinde et al, 2008). Development of milk substitutes extracted from legume serves as an alternative way of producing an acceptable nutrious food.

Soybean (Glycine max) is rcognized as one of such legume crops with huge potential the world over. This plant has been exploited for the manufacture of food products with soymilk identified as one of the promising products (Osundahunsi and Awor, 2005, Kolapo and Sanni, 2-005).

Soymilk is a fine, off-white or creamy emulsion, which resembles cow milk in both appearance and consistency (Soya Be, 2006). The increasing popularity of soymilk as a beverage worldwide (Dashiell et al, 1990) is credited to it health benefits. For example, low cholesterol and lactose levels, its ability to reduce bone loss and menopausal symptoms, prevention and reduction of heart disease and certain cancers (Soya Be. 2006). The attendant increase in the rate of soymilk consumption has encouraged low-scale production of the milk under house-hold conditions with little or no regard to quality control measures.

Consumers are increasingly aware of the effect of good diet on their well being and health soymilk is not only consumed for refreshment, but also to increase well being and to help in preventing health related disorders. An increasing number of consumers prefer minimally processed products from natural raw materials for reducing the intake of chemical additive from food and for obtaining products with improved nutritive and 
sensory characteristics (Iwe. 1991). The greatest problem associated with soymilk remains its beany flavor and very short shelf life due to microbial activity. The nutritious nature of soymilk however, makes it prone to microbial attach if not properly processed and stored as the nutrients it contains are also required for the growth of most spoilage organisms. A large number of microorganisms such as mesophilic aerobic bacteria, coliforms and fungi are known to be responsible for the spoilage of soymil, producing undesirable changes in milk (Momoh et al., 2011). It is therefore of paramount importance to subject soymilk production to a reasonable degree of hygiene. This coupled with the effect of refrigeration could help in extending the shelf-life. The presence of coliform bacteria in soymilk generally provides an index of the hygienic standard of soymilk and its keeping quality (adeleka et al. 2000). Control of microbial growth and spoilage of product is achieved by restricting and controlling microorganisms from contaminating the product through good manufacture and handling practice (Ofoefule, 2002).

\section{Aims and Objectives}

The aims and objectives of this research work is to initiate the production of soymilk and evaluate the microbiological quality of the soymilk when kept at ambient (room) and refrigeration temperature.

\section{Materials And Methods}

\section{Materials}

\section{Collection of Sample material}

The major material used for this research work, the soybean seed was purchased from Umuahia central Market. The commercial varieties, which are spherical and yellow in colour where used for the soymilk production.

\section{METHODS}

\section{Sterilization of materials}

All glassware used in the course of this research work were washed and sterilized in an oven. The grinding machine used for the processing of the soybean sees was rinsed with clean water, cleaned with ethanol and re-washed with clean water. Other materials were sterilized using ethanol. The cloth used for filtration was soaked in ethanol before being rinsed in clean water.

\section{Sample Preparation}

Soymilk was produced locally using the flowchart for soymilk production in figure 1 as reported by Lee et al., (1990). 200g of the soybean seed was cleaned, sorted (to remove cracked, damaged and discloured seeds) and winnowed. This was then soaked in two litres of clean water for $8-10$ hours. The water was changed at three hours interval. The beans were then parboiled in water for 45 minutes with constant agitation. The boiled beans were then allowed to cool, dehusked, thoroughly washed and homogenized with clean water into a paste using a grinding machine. The paste obtained was sieved using a clean muslin cloth to separate the milk (filterate) from the paste. The milk thus obtained was pasteurized by boiling to inactivate bacteria thereby prolonging shelf-life.

$200 \mathrm{~g}$ of soybean seeds

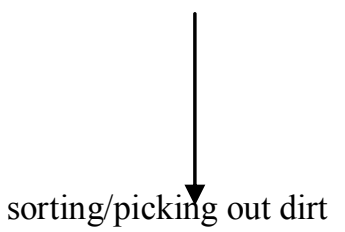

soaking in clean water for $8-10$ hours

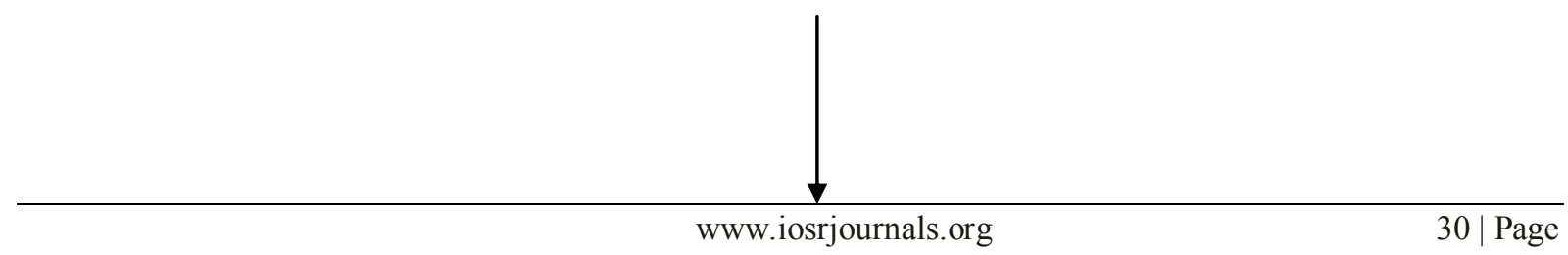


Boiling for 45 minutes

Washing and dehusking

Rinse in water and ground into paste

$\mid$

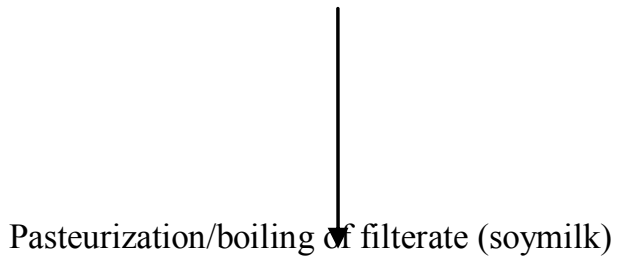

Fig 1: flow chart for soymilk production (Lee et al., 1990).

\section{Shelf-Life Studies}

The soymilk derived from the soybean seeds were divided into two clean bottles having screw corks. The bottles were tightlyscrewed and stored under two different conditions for shelf life studies. One of the bottles was stored at room temperature $\left(27+2^{\circ} \mathrm{C}\right)$ and the other at refrigeration temperature $\left(4^{\circ} \mathrm{C}\right)$ to monitor the occurrence of various bacterial isolates and the vable bacterial counts during decomposition. Shelf-life studies were carried out immediately after production ( 0 hour) and after every 24 hours thereafter, until each of the bottles were determined spoilt. Bad odour. Bad taste and separation of the milk into two distinct portions (curdling), were indicative of spoilage in each of the bottles.

\section{Methodology for total viable count (Serial Dilution)}

$1 \mathrm{ml}$ of the soymilk sample was picked with the aid of a sterile pipette after vigorous shaking. A plastic rack was arranged with sterile test tubes containing $9 \mathrm{ml}$ of sterile distilled water. A ten fold serial dilution (Dhawale and LaMaster, 2003), was carried out by dropping $1 \mathrm{ml}$ of the sample into the first test tube labeled 101. This was mixed properly. $1 \mathrm{ml}$ was again taken from the 10-1 dilution tube and transferred into the next test tube labeled 10-2. The dilutions continued to dilution 10-5. Each test tube was vigorously shaken before each transfer.

\section{Inoculation}

The pour Plate method (Dhawale and LaMaster, 2003) was used in plating all the samples. $1 \mathrm{ml}$ from dilution 10-3 was dropped into sterile petri dish with the aid of a sterile pipette. A molten Nutrient agar, mannitiol salt agar, macConkey agar, deMan Rogosa and Sharpe agra and Potato Dextrose agar were poured into the several Petri dishes containing $1 \mathrm{ml}$ of diluted sample. The plates were rotated clockwise for easy mix up of the sample and the media. All plates were allowed to solidify on the bench. All plate samples were duplicated. All media were prepared by weighing appropriate amount of the powder according to manufacturer's specification

\section{Incubation}

The potato dextrose agar plates were transferred into an incubator at $25^{\circ} \mathrm{C}$ for $3-5$ days while the other plates for bacteria isolation were transferred into another incubator at $37 \mathrm{oC}$ for $18-24$ hours. 


\section{Counting of the Colonies}

After incubation of all the plates, counts of the number of colonies in each plates was done with a hand tally counter (Dhawale and LaMaster, 2003). A mean of the count was obtained and multiplied with the appropriate diluting factor. The mean count was calculated as shown below.

Mean $=$ total Viable Count

Number of plates

The estimation of viable number of microorganisms (total viable counts) in each samples was made in colony forming units (cfu)

$\mathrm{TVC}=1$

Weight of sample *N*D

Where $\mathrm{N}=$ average number of colonies

$\mathrm{D}=$ dilution factor

\section{Isolation of Microorganisms from soymilk Sample}

The soymilk samples (ambient and refrigeration) were diluted in a ten-fold serial dilution as stated above. The pour plate method of incubation was used in plating all the samples. $1 \mathrm{ml}$ from the 10-3 dilution tube was dispensed into several sterile Petri dishes with the aid of a sterile pipette. Molten Nutrient agars, MacConkey agar, deman Rogosa and Sharpe agar, mannitol salt agar and potato dextrose agra were poured into the plates. The plates were rotated for easy mix up of the sample and the media. All plates were allowed to solidify on the bench. Each plated sami;e was duplicated.

All the potato dextrose agar plates were transferred into an incubator at $25 \mathrm{oC}$ for $3-5$ days while the other nutrient plates sample was duplicated.

All the potato dextrose agar plates were transferred into an incubator at $25 \mathrm{oC}$ for $3-5$ days while the

other nutrient plates were transferred into another incubator at $37 \mathrm{oC}$ for $18-24$ hours. All the incubated plates were examined daily for mycelia and colony growth.

\section{Sub- Culture and purification}

After incubation period, discrete colonies from bacteria plates were picked with a flamed wire loop and sub-cultured onto a newly prepared nutrient agar plates. Also, a flamed knife was used to sub-culture different colour of mycelia growth from potato dextrose agar plates onto a newly PDA plates. All plates were incubated appropriately. All nutrient plates were transferred into an incubator at $37 \mathrm{oC}$ for $18-48$ hours while all the PDA plates were incubated at $25 \mathrm{oC}$ for $3-5$ days. Purified colonies and mycelia were transferred into slants and stored properly for further characterization.

\section{Characterization of purified cultures *Fungi)}

Macroscopic examination was done by physical characteristics of the mycelia for colour and structure. Microscopic characteristics were also done through the morphological structure according to bernette and Hunter (1987). A wet mount method (Dhawale and LaMaster, 2003) was done before viewing the isolates under X40 objective of the microscope. The morphological structures include septate, non- septate, presence of sporangiophores, fruiting bodies and special organism like rhizoids etc. each morphological structure of each isolate was matched with a mycology atlas (Bernette and Hunter, 1987) for identification.

\section{Characterization of purified Culture (Bacteria)}

Each purified bqcteria was examined macroscopically for colony morphology, microscopically and then gram stained to determine the gram status. Characterization of the bacterial isolates was done through some standard biochemical tests. Sugar fermentation test were also carried out and recorded. The results were matched with a bacteriology atlas (Buchanan and gibbons, 1975). The biochemical tests analyzed were as follows. Catalase, Indole, methyl red, voges-Proskauer, Urease, H, S.

\section{Methylene blue test (Methodology)}

This test was used to check the contamination of bacteria in the sample of soymilk. It tells us about the vable count of bacteria that may be present in the milk. It is equally used to know the quality of the milk and in which quantity bacteria invaded the milk.

Principle: This test is based on the principle that if viable bacteria are present in the milk, they will reduce the methylene blue dye and decolourize the sample if kept for sometime. The methylene blue is reduced due to depletion of oxygen in the milk as it is consumed by bacteria. The bacteria in milk ferment lactose to lactic acid. During this process, electrons are released, which are taken up by methylene blue and results in its reduction and 
ultimately decolouration so, more bacteria will produce more electrons, in turn it would result in faster reduction and rapid decolouration.

\section{Procedure}

The samples (ambient and refrigerated soymilk) to be analyzed were well mixed and $10 \mathrm{ml}$ of each was poured into a clean and sterilized test tube.

With the aid of a sterile pipette, $1 \mathrm{ml}$ of methylene blue dye was added into the soymilk samples Gently. The test tubes were then closed with a rubber stopper and turned slowly so that all the contents (soymilk and methylene tue) mixed together. the test tubes were placed in a water bath at $37 \mathrm{oC}$ for half an hour making sure that water level was at a sufficient height of the testtubes. The soymilk was examined after 30 minutes for decolouration of the mixture. A control tube was also set up in which no methylene blue dye was added. It contained only the milk sample.

\section{Interpretation}

If viable bacteria decorlorize the milk within 30 minutes, then the test is positive and the milk is of unsatisfactory quality. If the milk is not decolorized within 30 minutes, then the test is negative and the milk is of good quality.

\section{Gram Staining method}

Gram stain was carried out to help to identify bacteria isolate from the microscope. A heat fixed smear of the isolated organism was made on a clean grease free slide and flooded with crystal violet solution for one minute. This was rinsed under slow running tap water, and then flooded with Lugols iodine solution for one minute. The slide was rinsed under slow running tap water and then decolourized drop-wise with acetone for two minutes. After which the slide was rinsed under slow running tap water and then counter stained with Safranin for 30 seconds. The slide was rinsed, air dried and viewd with a magnification of X100 using oil immersion

\section{Biochemical Tests}

Catalase test : the catalase test was done using a glass slide with a wireloop, cells were transferred from the centre of a well isolated colony. 1-2 drops of 3\% hydrogen peroxide was added to the slide. a positive result is indicated by the rapid appearance of sustained gass bubbles. No bubble production shows negative result.

Hydrogen Sulfide Test. Tubes of sterile peptone medium were inoculated separately with the test organisms using some uninoculated medium tubes as control.. in each tube, a strip of lead acetate paper was inserted to hang well above the medium and held at the neck of the tubes with stoppwer. They were incubated at $37 \mathrm{oC}$ for up to one week being examined daily for the presence of blackening at the cover end of the acctate paper indicating a positive result.

Indole test (Using Kovac's reagent) Tryton water was added to the test organism in a test tube and incubated at $37 \mathrm{oC}$ for 48 hour $0.5 \mathrm{ml}$ of Kovac's reagent was added and shaken properly, then examined after one (1) minute. A red colour ring in the tube indicated the presence of indole (positive reaction). No red colour indicated negative result.

Urease test the test organism was inoculated into urea agar slope using a sterile wire loop. This incubated at 37 oc for $18-24$ hours. A reddish -pink medium indicated a positive result (urease production). No red pink colour indicates negative result.

Methyl Red test: two drops of methl red solution was added to the test organism, shaken and examined for colour change Red colour indicated a positive reaction

Voges Proskauer test. Samples from methyl red test were tested further in the voges proskauer test. $0.6 \mathrm{ml}$ Dnaphtol solution and $0.2 \mathrm{ml}$ of aqueous $40 \% \mathrm{KOH}$ were added and shken. The test tubes were kept in slanting position and examined after 15 minutes. A strong red colour indicated a positive result.

Sugar Fermentation Test: the test was carried out using these sugars: sucrose, glucose, lactose, mannitol, and xylems. The test identifies organisms capable of utilizing the sugar concerned. The medium was prepared using $1 \%$ sugar peptone and two drop of indicator solution. After mixing thoroughly it was dispensed into test tubes and Durham tubes were dropped into the test rtubes in inverted position. The test tubes were corked and sterilized in autoclave at $121 \mathrm{oC}$ for 156 minutes. After cooling the test organism were inoculated into different tubes and incubated at $37 \mathrm{oC}$ for 48 hours. Gas production in the Durham tube and colour change from yellow to pink indicated a positive gas and acid production respectively.

\section{Physical Observation}

The indices of physical changes observed were odour, colour and whey separation 


\section{Statistical Analysis}

A two way analysis of variance (ANOVA) was performed to determine the effect of storage condition and type of growth medium on the growth microorganisms associated with soymilk spoilage.

\section{Results}

The result of total viable count observed from the refrigerated and ambient stored soymilk as shown in table 1 show that the refrigerated sample recorded lower count than the ambient stored sample. The values obtained for the microbial counts were a mean of three counts. The result of statistical analysis showed that there was significant treatment effect which entails that storage at refrigeration temperature played a major role in controlling the microbial load of the spoilage microorganism as compared to the one stored at ambient temperature.

Table 2 depicts all the bacterial and fungal isolates that were isolated from the studies soymilk simple. The quality status of the soymilk is shown in table 3. This was obtained from the methylene blue dye reduction test. Table 4 shows the morphological, Gram status and some biochemical characteristics of the bacterial isolates shown in table 2.

The microscopic description of the fungal isolates is shown in table 5. The $\mathrm{pH}$ of the stored soymilk decreased with days of storage as shown in table 7. Table 6 shows the physical changes observed in the soymilk samples during the course of storage. The changes included change in colour, production of odour.

Table 1 below shows the total viable counts from different selective media on refrigerated and ambient stored soymilk.

Table 1: Effect of storage at ambient and refrigeration temperature on soymilk

\begin{tabular}{|c|c|c|c|c|c|c|}
\hline Day & $\begin{array}{l}\text { Storage } \\
\text { Condition }\end{array}$ & $\begin{array}{l}\text { NA } \\
\text { TVC } \\
\text { efu/ml }\end{array}$ & $\begin{array}{l}\text { MSA } \\
\text { TVC } \\
\text { efu/ml }\end{array}$ & $\begin{array}{l}\text { MCA } \\
\text { TVC } \\
\text { efu/ml }\end{array}$ & $\begin{array}{l}\text { PDA } \\
\text { TVC } \\
\text { efu/ml }\end{array}$ & $\begin{array}{l}\text { MRS } \\
\text { TVC } \\
\text { efu/ml }\end{array}$ \\
\hline 1. & Ambient & $\begin{array}{l}2 \times 10^{3} \\
1 \times 10^{3}\end{array}$ & $1 \times 10^{1}$ & $2 \times 10^{3}$ & - & - \\
\hline 2. & $\begin{array}{l}\text { Ambient } \\
\text { Fridge }\end{array}$ & $\begin{array}{l}5 \times 10^{3} \\
2 \times 10^{3}\end{array}$ & $\begin{array}{l}3 \times 10^{3} \\
1 \times 10^{3}\end{array}$ & $\begin{array}{r}3 \times 10^{3} \\
1 \times 10^{3}\end{array}$ & $\begin{array}{c}2 \times 10^{3} \\
1 \times 10^{3}\end{array}$ & $\begin{array}{l}4 \times 10^{3} \\
1 \times 10^{3}\end{array}$ \\
\hline
\end{tabular}

\section{Discussion}

\section{Discussion And Recommendation}

Soymilk remains a very important local beverage in most parts of Africa and other parts of the world. Its high protein level has made it so irresistible as an alternative source of plant protein. However, the processing and storage conditions influence the presence or absence of spoilage organism in the soymilk where they multiply and cause undersired effects. This beverage is prepared locally at homes usually under unhygienic conditions and thus is prone to contamination by the micro flora of the raw materials and of the utensils.

From the shelf life study, it was observed that the soymilk product was good for consumption as at the second day of production when stored at room temperature and four days after production for the refrigerated sample. This is evident from result of the Methylene blue dye reduction test (table 3), which showed that the total number of viable bacteria could only cause spoilage after 2 and 4 days respectively for ambient and refrigerated samples. This goes to prove that further quality by inhibiting growth of certain bacteria.

The initial $\mathrm{pH}$ of the sample was near neutrality at 6.8 (table 7) before decreasing to 5.6 on the second day due to the activities of lactic acid bacteria. The $\mathrm{pH} 7.2$ for soymilk as reported by Adeleke, et al., 2000 falls within the range obtained in this study, which incidentally favours bacterial growth.

The colour of the soymilk was creamy on day 1 after production. This colour was retained until day 4 (table 6). It turned to dark cream colour on day 5 and 6 . This change may have resulted from microbial activities in the soymilk. Whey separation was observed on day 3 (table 6). The day corresponds to the day when appreciable changes in microbial load was observed (table 1). Odour change was observed in the soymilk on day 4 after whey separation. This shows that the microbial load effected changes in the soymilk during storage. 
The detection of Eschericia coli and staphylococcus aureus which were also among the isolates deterted by Kolapo and Oladimeji, 2008, reflects a poor hygienic standard in the production process of soymilk. Most strains of staphylococcus aureus are known to be pathogenic, due mostly to the heat stable entertoxin they produce in direct relationship to their inoculums level Considering the notoriety of the resistance of Staphylococcus aureus to Methicilin and other penicillin, its detection in the soymilk sample, poses a serious health hazard to consumers. The load of microorganisms increased as the day increased (Fig 2 and 3). However, the increase in microbial load was more pronounced in fig 2 (ambient storage) as compared to fig 3 (refrigerated sample).

Generally, pasteurization must have destroyed most growing organism in the soymilk product that would have caused the spoilage earlier than was observed. The combined effects of pasteurization and refrigeration (Low temperature) storage also controlled the proliferation of the organism.

Organisms that grew at room temperature which is slightly close to body temperature $\left(37^{\circ} \mathrm{C}\right)$ could as well survive the body temperature and in this case, they become pathogenic to human. This is in contrary to those that grew at refrigeration temperature which cannot withstand the body temperature.

The occurrence of Bacillus spp and presence of Lactobacillus spp on day 2 which is similar to what was obtained by Kayode et al., 2005, may have initiated spoilage in the soymilk and the noticeable increase in acid production as seen in the $\mathrm{pH} 5.6$ (table 7) Lactobacillus poasses galactosidase and is able to utilize galactoligosaccharides like reffinose and stachyose in soymilk for growth and acid production. The presence of LAB which was also observed by kayoed, et al, 2005, was not surprising as these organisms thrive in medium rich in fermentable substrates as sugar which can be degraded with production of acid.

Low temperature storage controls the proliferation of organisms present. This must be responsible for the low microbial counts in the refrigerated samples as compared to the ambient stores sample.

From the result of statistical analysis, there was significant treatment effect which prevented the proliferation of the spoilage microorganisms. This means that refrigeration as a treatment had significant effect in reducing the multiplication of the spoilage organism as compared to the sample stored at room temperature.

\section{Recommendation}

In view of the continued dairy milk shortage or absence in developing countries, there is the need for increased production of soymilk while maintaining good manufacturing practices. The raw material for soymilk production (soybean) can grow in many parts of the world all season and cultivation of soybean is relatively easier than production of dairy cow. The refrigerated sample soymilk recorded lower bacterial viable counts than the one stored at ambient (room) temperature. Thus with adequate adherence to quality control measure during production and coupled with effect of proper storage, acceptable standard can be achieved in the production and utilization of soymilk.

\section{Contribution to Knowledge}

From this research work, it is clearly seen that different microorganism operates within different temperature ranges (Higher temperature enhance proliferation of microorganisms). The effect of refrigeration on the soymilk sample goes further to prove this fact. It was also gathered that pasteurization (boiling) has its way of inhibiting or reducing the activities of disease causing organisms.

\section{Suggestion for further Studies}

A combination of preservative coupled with subjection to pasteurization and refrigeration could help in extending the shelf-llife beyond the level observed in this work. The effect of certain preservatives at various concentrations also with pasteurization and refrigeration storage of the locally made soymilk will enhance the keeping quality of the soymilk. These preservatives will help prevent early spoilage of the soymilk by disrupting critical cell factors or denature cell proteins.

\section{References}

[1]. Adegoke, G. O., Gbadamosi, R. Evwoerhurhoma, F., Uzo-Peters, P. I. falode, K. O., mandy, O and Skura, B. (2002). Protection of maize (Zea mays) and soybean (Glycine max) Uing Aframonum Donielli. Journal of European Food Research technology 214. 408411.

[2]. Adeleke, O.E. adeniyi, B. A. and Akinrinmisi. A. A. (2000). Microbiological Quality of Local Soymilk. A Public health appraisal. African journal of biomedical Research 3: 89-92.

[3]. Akeem, A. A., uduma, E. O. Christian, C. O. and Emmanuel, C. I. (2001). Evaluation of Microbiology Quality of some soybean Milk products Consumed in Nigeria. Prime Research on medicine 1(2) 25-30.

[4]. Ash M (2001) Soybeans. Back ground and issues for Farm Legislation. Electronic Outlook Report, Economic research Service US Department of Agriculture. 
[5]. Bennete. H. L. and hunter, B. B. (1987). Blustrated Genera of Imperfect Fungi $4^{\text {th }}$ edition $\quad$ Macmillan Publishing Company, New York. Pp. 128.

[6]. Blackman. S. A. Obendorf, R. I. and Leopold, A. C (1992). Maturaion Proteins and Sugars in Desiccation Tolerance of Developing Soybean Seeds "Plant physiology (American Society of plant biologist) 100 (1): 225-30.

[7]. Buchanan, R. E. and Gibbons, N. E. (1975). Bergey's Manual of Determinative Bacteriology.The Williams and Wikkians Company, Baltimore. Pp 78.

[8]. Da Mota, f. S (1978). Soybean and the Weather Technical Note No. 160. WMO No. 498. World meteorological Organization, Geneva Switzerland.

[9]. Dashiell. K. E., Singh, S. R., Nakaayama, O., Ogundipe, H. O. and Akeem. C. N (1990) Soybean Research at IITA GLIP Research Monograph No. 1 Ibadan

[10]. Dhawale, S. and LaMaster, A. (2003). Microbiology Laboratory manual. The mcHill Company.Inc. USA.

[11]. FAOSTAT (2001). Production crops, Cassava. Soybean. Food and Agriculture Organization www.fao.org/soybean.html. Accessed 22nd September, 2012.

[12]. Fargione, J., Hill. J. tilman, D., Polasky. S and Hawthorne. P. (2008) "Land Clearing and the Biofuel carbon Debi" Science 319 (5869): 1235-18.

[13]. Farinde, e. O., Obatolu, V. A Oyarekwa, M. A. Adeniran, H. A., Ejoh, S. I. and Olanipekan, O. I.(2010). Physical and Microbial properties of fruit flavoured fermented Cow milk and Soymilk under different temperature of storage. African Journal of Food Science Technology 5: 120 -127.

[14]. Gesinde, A. T. Ovawove, O. M. and adebisi, a (2008). Comparative Studies on the Quality and Quantity of Soymilk from Differen Varieties of soybean Pakistan Journal of Nutrition 7 (1): $157-60$

[15]. Gavin, M. and Wettstein, A. (1990). "Soymilk and Other Soya products from the Traditional Methods of production to the New manufacturing processes" Buhier Ltd, Switzerland Hauman, B. F. (1984). Soymilk. New Processing, packaging Expand markets. Journal of Ameriacan Oil Chemical Society 61: 1784-8.

[16]. Heckman, J. R., Angle, J. S. and Chaney, R. L., (1985). Residual effects of Sewage Sludges on Soybean Accumulation of soil and symbiotically fixed Nitrogen Journal of environmental Quality 16 (2) 118-124

[17]. Henkel, J. (2000). "Soy Health Claims For soy proteins. Questions about Other components"FDA Consumer (Food and Drug Administration) 34 (3). 18-20.

[18]. IITA (International Institute of tropical Agriculture, 1989). Soybeans for good Health. How to Grow and Use Soybean in Nigeria IITA Ibadan, Nigeria. Pp. 22

[19]. Ikeh E. I., Okwudili, P. E. Agino, e. S. and Odumodu, C. U. (2001). Microorganisms associated With locally available infant Weaning foods in Jos and Environs, Nigeria. NigerianJournal of paedriatics 28 (1) 7-13

[20]. Iwe. M.O (1991) pattern of spoilage of soymilk: Influence of preparation methods and Storage Conditions. Nigerian Food journal 9: $92-104$

[21]. Johnson, W. K. and Snyder, H. E. (1978). Soymilk Comparison of processing method, Yield And Composition Journal of food science 43: 349-52

[22]. Kayode, R. M. O. Akinyoseye, F. A. and Arotupia, D. J. (2005). Comparative Evaluation of the Bacteria isolated from decomposing. Cow milk and Soymilk Journal of AgricultureResearch and Development 4 (2). 40 - 45Kolapo, A. L and Oladimeji. G. R. (2008) 